\title{
Erratum to: Thromboelastometry and platelet function during acclimatisation to high altitude
}

\author{
Alistair S. Rocke ${ }^{1}$ Gordon G. Paterson ${ }^{1,2}$ Matthew T. Barber ${ }^{1} \quad$ Alexander I. R. Jackson $^{1,3}$ \\ Shona E. Main ${ }^{1}$ Calum Stannett ${ }^{1}$ Martin F. Schnopp ${ }^{1}$ Martin J. Maclnnis ${ }^{4}$ J. Kenneth Baillie ${ }^{1,5}$ \\ Elizabeth H. Horn ${ }^{6}$ Carl Moores $^{7}$ Paul Harrison ${ }^{8} \quad$ Alastair F. Nimmo $^{7} \quad$ A. A. Roger Thompson ${ }^{1,9}$
}

\footnotetext{
${ }^{1}$ Apex (Altitude Physiology Expeditions), Edinburgh, United Kingdom

2 Edinburgh Medical School, University of Edinburgh, Edinburgh, United Kingdom

${ }^{3}$ Clinical and Experimental Sciences Academic Unit, University of Southampton, Southampton, United Kingdom

${ }^{4}$ Department of Kinesiology, McMaster University, Hamilton, Ontario, Canada

${ }^{5}$ Division of Genetics and Genomics, The Roslin Institute, University of Edinburgh, Edinburgh, United Kingdom

${ }^{6}$ Department of Clinical Haematology, St James's University Hospital, Leeds Teaching Hospitals NHS Trust, Leeds, United Kingdom

7 Department of Anaesthesia, Critical Care and Pain Medicine, Royal Infirmary of Edinburgh, NHS Lothian, Edinburgh, United Kingdom

8 Institute of Inflammation and Ageing, College of Medical and Dental Sciences, University of Birmingham, Birmingham, United Kingdom

${ }^{9}$ Department of Infection, Immunity and Cardiovascular Disease, University of Sheffield, Sheffield, United Kingdom
}

\section{ERRATUM}

In the Original Article by Rocke et al. "Thromboelastometry and platelet function during acclimatization to high altitude" (Thromb Haemost 2018; 118: 063-071) after publication of the article it has come to the corresponding author's attention that an author was inadvertently omitted from the manuscript. The author, Martin MacInnis, made a significant contribution to: 1. initiating the coagulation research that led to the manuscript, 2. designing the research protocol and performing the initial data analysis, 3. recruiting volunteers, writing applications for ethical approval and making other logistical arrangements that were necessary to complete the study. Martin MacInnis has read and approved the published version of the manuscript. Furthermore, a middle initial was added to the updated list (Shona E. Main) and misspelling of Elizabeth Horn's surname was corrected. The amended author list is as above.
DOI https://doi.org/ $10.1055 / \mathrm{s}-0038-1639337$. ISSN 0340-6245. (c) 2018. The Author(s).

This is an open access article published by Thieme under the terms of the Creative Commons Attribution-NonDerivative-NonCommercial-License, permitting copying and reproduction so long as the original work is given appropriate credit. Contents may not be used for commercial purposes, or adapted, remixed, transformed or built upon. (https://creativecommons.org/ licenses/by-nc-nd/4.0/)

Georg Thieme Verlag KG, Rüdigerstraße 14, 70469 Stuttgart, Germany 